\title{
La huella romántica en la restauración monumental decimonónica en España
}

\author{
Silvia GARCÍA AlCÁZAR \\ Universidad de Castilla-La Mancha
}

\begin{abstract}
RESUMEN
Este estudio pretende abordar el tema de la conservación arquitectónica decimonónica poniendo el acento en el contexto ideológico que le dio origen: el Romanticismo.

Con la llegada del mismo la percepción del arte y el patrimonio cambió por completo. El hombre se erigió como el único agente capaz de juzgar lo bueno y lo malo en el campo del arte y la estética, dejando atrás la jerarquía de estilos para dar paso a la valoración de manifestaciones hasta entonces denostadas como la Edad Media. A partir de entonces los edificios medievales cristianos fueron revestidos de contenidos políticos y religiosos mientras que la arquitectura islámica, por su parte, destacaba por su carácter exótico y evocador que acercaba a Oriente al curioso que la miraba sin salir de nuestro país. La vuelta a la Edad Media no solo fue ideológica sino también material de manera que se quiso devolver a aquellos monumentos su supuesta imagen original. En este sentido, se siguieron los parámetros ideales enunciados por Viollet-Le-Duc, para quien había que devolver al monumento una imagen que quizás nunca había tenido. En España esta teoría tuvo su plasmación práctica en las intervenciones de edificios paradigmáticos como la catedral de León, la iglesia de San Martín en Frómista (Palencia) o el recinto de la Alhambra de Granada.
\end{abstract}

Palabras clave: Monumentos; restauración; España; siglo XIX; Pintoresquismo.

\section{The romantic influence on the nineteenth-century architectural restoration in Spain}

\begin{abstract}
This research aims to address nineteenth-century architectural conservation from a different perspective, as it explores some of the paradigmatic restorations generated in Spain with an emphasis on the ideological context that gave rise to them: Romanticism.

With the advent of Romanticism, the perception of art and heritage completely changed. Man emerged as the only agent capable of judging good and bad, leaving out the mandates of the Art Academies for which good taste could only be achieved in one direction: Classicism. Since then, it is wanted to return to the Middle Ages in every sense and, as a consequence, the restoration of medieval buildings, forgotten until those days, became more and more important. Christian buildings were covered by religious and political content, while Islamic architecture was admired for her exotic and evocative nature. We could travel to the Middle East without leaving Spain.

The return to the Middle Ages was not only ideological but also material so as to return to those monuments the alleged original image by means of following ideal parameters. According to E. E. Viollet-LeDuc, the most important thing was returning to the monument an image that perhaps it never had. In Spain, this theory had its manifestation in the interventions of buildings like the Cathedral of Leon, the church of St. Martin in Frómista (Palencia) or the Alhambra in Granada.
\end{abstract}

Keywords: Monuments; restoration; Spain; nineteenth century; Picturesqueness 
El presente texto tiene su origen en la comunicación expuesta en el II Encuentro de Jóvenes Historiadores del Arte celebrado entre los días 28 y 30 de abril de 2010 en la Facultad de Geografía e Historia de la Universidad Complutense de Madrid. El objetivo de la intervención fue dar a conocer la que había sido mi investigación durante los últimos cuatro años y que había visto la luz en forma de Tesis Doctoral. Ésta llevó por título La ideología romántica en la restauración monumental en España durante el siglo XIX; se había realizado en el marco del Departamento de Historia del Arte de la Universidad de Castilla-La Mancha y había sido defendida en noviembre de 2009, obteniendo la calificación de Sobresaliente Cum laude por unanimidad.

El objetivo principal de la misma era estudiar en profundidad el papel decisivo que el Romanticismo jugó en la teoría de la restauración y constatar la presencia del mismo en la práctica restauradora de monumentos en nuestro país. Para ello, se partió del análisis tanto del contexto general de la restauración arquitectónica como de la génesis teórica del propio Romanticismo. Pero, sin duda, la finalidad esencial fue la de abordar el tema de la restauración monumental decimonónica desde una perspectiva diferente. La mayor parte de los estudios que tenían como argumento central la restauración decimonónica en España solían presentar una estructura similar basada en la enumeración de los monumentos restaurados y las intervenciones experimentadas, aludiendo levemente al contexto ideológico que les había dado origen. Sin embrago, con esta investigación se quiso dar prioridad a ese contexto, al conjunto de hechos y cambios sociales y, muy especialmente, ideológicos sin los cuales nunca hubiera sido posible la realización de determinadas intervenciones. Con la llegada del Romanticismo la conservación del patrimonio se abordó desde parámetros novedosos asentados precisamente en una manera de ver la vida igualmente novedosa. Esas innovaciones fueron constatadas a través del análisis de los proyectos que algunos de los arquitectos restauradores más renombrados elaboraron para monumentos capitales de la historia de la arquitectura de España.

La metodología utilizada fue eminentemente bibliográfica así como de trabajo de archivo. En primer lugar, se partió del análisis de obras relacionadas tanto con el ámbito de la restauración en general como con la conformación y desarrollo del Romanticismo. Gracias a la lectura y estudio de las mismas se pudo conformar una primera parte más teórica que sirvió de soporte a la parte práctica de esta tesis. Esa parte práctica conformaba la pieza más relevante de la tesis y fue elaborada en gran medida gracias a una importante labor de archivo llevada a cabo en la Real Academia de Bellas Artes de San Fernando así como en el Archivo General de la Administración de Alcalá de Henares, en cuyos fondos se encontraban las memorias de restauración elegidas como objeto de estudio.

El siglo XIX español se caracterizó por ser uno de los más convulsos y agitados de nuestra historia con acontecimientos como la Guerra de la Independencia, las desamortizaciones o las continuas luchas carlistas. Como consecuencia de ello, el patrimonio quedó marcado para siempre con señales, testigo de aquellos hechos. 
Incluso hubo obras y edificios que se perdieron irremediablemente ${ }^{1}$ dejando en los intelectuales y apasionados del arte de la época una honda sensación de pérdida. Esto quedó perfectamente reflejado en palabras como las del conde de Campo Alange en la revista El Artista:

"Llegó la guerra de la independencia; y consecuencia de ella fue un roze [sic] más inmediato de nacionales con estrangeros [sic]. Entonces pudieron estos ver nuestra riqueza; y ya aprovechándose de nuestra ignorancia, ya valiéndose del brutal derecho de la fuerza, se hicieron dueños de innumerables pinturas de nuestros más célebre profesores (...) No se puede dar un paso por la Península, sin hallar vestigios del vandalismo de la guerra"2

Tradicionalmente, la arquitectura había sido vista como la prolongación de los ideales sociales y políticos de una época determinada. Tal consideración le ha hecho soportar a lo largo de la historia todo tipo de atropellos causados por aquellos que querían terminar con todo vestigio de una época anterior o, que sencillamente, buscaban una modernidad reñida con sus orígenes. De este modo, algunos de los ejemplos de la arquitectura patria fueron destruidos de manera indiscriminada o sencillamente abandonados a su suerte hasta sufrir un agónico y triste final. Ante tal situación, comenzaron a aparecer con fuerza las primeras voces a favor de la salvaguarda del patrimonio monumental al igual que ya ocurriera en Francia tras la Revolución ${ }^{3}$.

Aunque ya desde la Edad Media se han querido ver en determinadas intervenciones un interés por perpetuar los edificios ${ }^{4}$, lo cierto es que no fue hasta el siglo XVIII cuando España comenzó a dar muestras claras de interés por la conservación arquitectónica gracias a la puesta en práctica de ciertas medidas proteccionistas ${ }^{5}$. Uno de los grandes precedentes lo encontramos en la creación de las principales academias que a partir de ese instante se erigieron como directas responsables, no solo de la creación artística sino también de la conservación del patrimonio monumental. En 1738 se creó la Real Academia de la Historia y en 1752 se hizo lo propio con la Academia de las Nobles Artes ${ }^{6}$. Paralelamente y desde 1761 la Corona

1 Véase GONZÁLEZ-VARAS IBÁÑEZ, Ignacio, Restauración monumental en España durante el siglo XIX, Valladolid, Ámbito, 1996, y BELLO, Josefina, Frailes, intendentes y políticos. Los bienes nacionales, 1835-1850, Madrid, Taurus, 1997.

2 CAMPO ALANGE, conde de, "Sevilla. La Catedral”, en El Artista, tomo II, $\mathrm{n}^{\circ}$ 18, 1835, p. 209. Este artículo incluido en la paradigmática revista ilustraba la situación vivida en torno al patrimonio durante la guerra contra los franceses.

3 A este respecto, véase la obra: RÉAU, Louis, Histoire du vandalisme. Les monuments détruits de l'art français, Paris, Robert Laffont, 1994.

4 Esto se desprende de algunos textos insertos en las Partidas de Alfonso X así como de las intervenciones del monje Escobedo en el Acueducto de Segovia en el siglo XV, por citar solo dos ejemplos. Véase MUÑOZ COSME, Alfonso, La conservación monumental del patrimonio arquitectónico español, Madrid, Ministerio de Cultura Dirección General de Bellas Artes y Archivos, 1989, p. 76.

5 Ibid., p. 22.

6 QUIROSA GARCÍA, Ma Victoria, "El nacimiento de la conciencia tutelar. Origen y desarrollo en Europa durante el siglo XVIII", en e-rph [en línea], no 2, 2008, p. 5. http://www.revistadepatrimonio.es/revistas/numero2/legislacion/estudios/_pdf/legislacion_estudios.pdf. 
encomendó, por Real Orden, la supervisión del patrimonio monumental a la Real Academia de Bellas Artes de San Fernando ${ }^{7}$.

Este camino se consolidó y tomó forma ya iniciado el siglo XIX con la creación de normativas y de teorías revolucionarias que hoy son la base para seguir mejorando en materia conservacionista. Las principales novedades aportadas por la teoría y la práctica restauradoras decimonónicas se deben a la aparición en escena del Romanticismo y su filosofía de vida donde se priorizaba el placer a través de la contemplación, algo que tuvo una grandísima influencia en la teoría y la práctica de la restauración del siglo XIX.

Hasta el momento el Clasicismo había marcado las pautas en creación artística pero con el Romanticismo éste entró en crisis. Así, comenzaron a valorarse manifestaciones al margen del gusto academicista que hasta entonces habían estado denostadas como ocurría con las medievales, abriendo así el abanico a nuevas posibilidades estéticas. Esto no hubiera sido posible sin un importante cambio ideológico fraguado poco a poco y que llegaría a su máxima expresión ahora con la exaltación de la "psicología del yo", es decir, con la legitimidad del gusto personal. Immanuel Kant (1724-1804) ya anticipó lo que sería esta gran revolución ideológica en su Crítica del juicio (1790), al apuntar que la experiencia estética surgía del sentimiento de la persona. Para él en la percepción se conjugaban aspectos sensibles y aspectos elaborados por el propio entendimiento, generando una complacencia incluso antes de percibir. Esa sensación placentera, común a todos los hombres, era la Belleza la cual era difícil de definir por estar relacionada con el sentimiento y el gusto. De este modo, la Belleza dejaba de ser impuesta para surgir de la experiencia del individuo con lo que se daba vía libre a la validez de los juicios de gusto ${ }^{8}$. Las academias dejaban de tener la capacidad de marcar lo que era bueno o malo en el campo del arte ya que la valoración del mismo dependía exclusivamente de los gustos de cada individuo. El origen de esa universalidad del gusto lo podríamos rastrear incluso hasta el siglo anterior en figuras como Joseph Addison (1672-1719) quien había sentado las bases del subjetivismo en su conocida obra Los placeres de la imaginación $n^{9}$.

Como consecuencia la Edad Media se convirtió en la gran protagonista del XIX y del gusto romántico. Esta apertura e innovación ideológica presenta consecuencias decisivas para la historia de la restauración monumental ya que los mo-

7 Véase ARBAIZA BLANCO-SOLER, Silvia, "La Academia y la conservación del patrimonio I", en Boletín de la Real Academia de Bellas Artes de San Fernando, $\mathrm{n}^{\circ}$ 89, $2^{\circ}$ semestre 1999, pp. 27-56. Véase igualmente, de la misma autora,"La academia y la conservación del patrimonio II", en Boletín de la Real Academia de Bellas Artes de San Fernando, $\mathrm{n}^{\mathrm{o}}$ 90, ${ }^{\text {er }}$ semestre 2000, pp. 27-58, para entender el papel de la institución también a lo largo del siglo XIX.

8 BOZAL, Valeriano (ed.), Historia de las ideas estéticas y de las teorias artísticas contemporáneas. Vol. II. Madrid, Visor, 1996.

9 ADDISON, Joseph, Los placeres de la imaginación y otros ensayos de The Spectator, Madrid, Visor, 1991, Edición a cargo de Tonia Raquejo. 
numentos fueron revestidos de contenidos trascendentales que los dotaron de una importancia inusitada, lo que generó una mayor preocupación por la pervivencia de los mismos. El mejor ejemplo lo encontramos en Alemania donde apareció un interesante movimiento cultural y político de índole nacionalista, que no dudó en asumir el estilo gótico como propio, viendo en la catedral la representación de su sentimiento común de unidad política y espiritual. A este fenómeno contribuyeron determinados amantes de la Edad Media que fomentaron el interés por el arte y la literatura del momento ${ }^{10}$ como Johann Georg Hamann y Johann Gottfried Herder, aunque fue Johann Wolfgang Goethe el que mejor supo plasmar ese sentimiento a través de su famoso Himno pronunciado ante la Catedral de Estrasburgo. En Alemania se supo dotar a la arquitectura gótica de contenidos que iban más allá de lo puramente constructivo viendo en ella además la mejor representación de la fe cristiana. Dichos contenidos llegaron también hasta Francia en relación a la renovación neocatólica acaecida como reacción al laicismo que estaba cobrando fuerza. En ese ámbito destacaron importantes figuras literarias que ensalzaron desde la escritura el papel de dicha arquitectura. Tal fue el caso de Chateaubriand con su Genio del Cristianismo ${ }^{11}$ y de Víctor Hugo con su famosa novela Nuestra Señora de Paris ${ }^{12}$ donde se dota a la arquitectura de una importante carga espiritual.

Con todo ello, la reivindicación y vuelta a la Edad Media era un hecho por lo que el siguiente paso natural fue el de recuperarla también de manera material. Aquellos monumentos que se ensalzaban en la literatura necesitaban ayuda para poder mantenerse en pie por lo que fue en este momento cuando comenzaron a formularse las más destacadas teorías conservacionistas.

En este sentido, los personajes más relevantes fueron Eugene Emmanuele Viollet-Le-Duc en Francia y John Ruskin en Inglaterra, cuyos planteamientos fueron, finalmente, llevados a la práctica por su discípulo William Morris. El primero, fue un apasionado de la edilicia medieval por lo que no dudó en aplicar a monumentos de esa época su famosa teoría de "restauración en estilo" enunciada en su Dictionnaire raisonné de l'architecture française:

"La palabra y la cosa son modernas. Restaurar un edificio no es mantenerlo, ni repararlo, ni rehacerlo, es devolverlo a un estado completo que pudo no haber existido nunca"13.

${ }^{10}$ HONOUR, Hugh, El Romanticismo, Madrid, Alianza, 2004 (1979), p. 162.

${ }^{11}$ CHATEAUBRIAND, François-Rene, vizconde de, El genio del Cristianismo o Bellezas de la religión cristiana. Madrid, Imprenta de Gaspar y Roig Editores, 1853.

12 HUGO, Víctor, Nuestra Señora de París. Madrid, Alba, 1998 (1831).

13 Traducción del original en francés: "Le mot et la chose sont modernes. Restaurer un édifice, ce n'est pas l'entretenir, le réparer ou le refaire, c'est le rétablir dans un état complet qui peut n'avoir jamais existé à un moment donné". VIOLLET-LE-DUC, Eugène Emmanuele, Dictionnaire raisonné de l'architecture française du XI ${ }^{e}$ au XVI ${ }^{e}$ siécle, Paris, Ve A. Morel \& $\mathrm{C}^{\mathrm{ie}}$ Éditeurs, 1875, t. VIII, p. 14. 
Viollet-Le-Duc apostaba por dotar a la construcción de una imagen ideal y mejorada algo que, sin embargo, no era del agrado de Ruskin. Aunque también era un fervoroso amante del medievo, consideraba que recuperar su esencia a través de la mejora de sus vestigios arquitectónicos era totalmente imposible, tanto como "resucitar a un muerto", tal y como él mismo apuntaba en Las siete lámparas de la arquitectura ${ }^{14}$.

Por su parte, el medievalismo español estuvo vinculado a las aportaciones, cargadas de imaginación, que desde el extranjero se hicieron sobre el país y su patrimonio. En este sentido, los viajeros y estudiosos tuvieron un importante papel, en especial los británicos, quienes alabaron notablemente nuestras grandes catedrales y su buen estado de conservación a pesar de los avatares bélicos decimonónicos, en comparación con las maltrechas catedrales francesas ${ }^{15}$ tras los efectos de la Revolución. Madrid fue uno de los centros españoles donde en primer lugar se sintió el medievalismo, dando pie a la finalización de lo que Pedro Navascués denominó como "la tiranía del estilo único", o lo que es lo mismo, fraguando los inicios de la crisis del Clasicismo y el final de la jerarquía de estilos ${ }^{16}$.

Como ocurriera en el resto de Europa, España vio en las catedrales góticas el alma de la auténtica historia patria de ahí que se lanzasen a restaurar las más notables. En este sentido, no podemos obviar que los avances generados por Ruskin a favor de la revalorización de lo medieval fueron determinantes pero lo cierto es que en nuestro país fueron las teorías intervencionistas de Viollet-Le-Duc las que triunfaron hasta el punto de mantener su vigencia incluso bien entrado el siglo inmediatamente posterior $^{17}$. Isabel Ordieres apuntaba algunos de los arquitectos nacionales que siguieron más fielmente a Viollet-Le-Duc como fue el caso de Juan de Madrazo, Demetrio de los Ríos, Arturo Mélida Alinari, Elías Rogent y Arturo Fernández Casanovas ${ }^{18}$.

Aunque fue la arquitectura gótica la verdadera protagonista de aquellos momentos no podemos dejar de hacer referencia a los edificios románicos. Su importancia no fue equiparable a la de las grandes catedrales e iglesias ojivales pero es interesante acercarse al modo en que se concebía este estilo. Los problemas a la hora de denominarlo y las dificultades para adentrarse en sus orígenes fue una constante en el ambiente romántico que llevó a los principales pensadores a elucubrar al respecto ${ }^{19}$.

\footnotetext{
${ }^{14}$ RUSKIN, John, The seven lamps of architecture, New York, John Wiley, 1849.

${ }_{15}$ MATEO, Matilde, "Sobre miradas y destrucciones: los británicos y la arquitectura medieval española", en Boletín de la Real Academia de Bellas Artes de San Fernando, no 90, 2000, p. 18.

16 NAVASCUÉS PALACIO, Pedro, Arquitectura y arquitectos madrileños del siglo XIX, Madrid, Institutos de Estudios Madrileños, 1973, p. 25.

17 ORDIERES DÍEZ, Isabel, Historia de la restauración monumental en España (1835-1936), Madrid, Ministerio de Cultura, 1995, pp. 115-123.

18 Ibid., pp. 132-138.

19 PANADERO PEROPADRE, Nieves, "La valoración de la arquitectura románica en la España del Romanticismo", en Anales de Historia del Arte, no 9, 1999, pp. 255-258. Véase igualmente el artículo de la misma autora: "La definición del estilo románico en la historiografía española del Romanticismo", en Anales de Historia del Arte, $\mathrm{n}^{\circ} 7,1997$, pp. 245-256.
} 
Si el gótico y el románico se hicieron protagonistas de la estética decimonónica por su carácter cristiano, el arte árabe lo hizo por su exotismo. Sus formas innovadoras y el halo misterioso y casi desconocido que rodeaba a Oriente, revestían a la arquitectura islámica de un aspecto atrayente que no se encontraba en otras manifestaciones.

Esta irrefrenable atracción que el orientalismo estaba ejerciendo sobre el hombre del XIX podía justificarse en el interés por adentrarse en una cultura ajena a la europea y, hasta cierto punto, primitiva. En aquellos paraísos lejanos era donde se encontraría la génesis de todo, un mundo diferente en el que vivir al margen de las reglas y en contacto con una naturaleza salvaje.

El descubrimiento definitivo de Oriente fue llevado a cabo por Napoleón Bonaparte con su invasión de Egipto en 1798, marcando con ello el inicio del orientalismo. Ello dio como fruto su Descripción de Egipto publicada en diversos tomos entre los años 1803 y 1828 . Ese mismo espíritu es el que acompañó a los viajeros y curiosos que desde entonces se acercaron a Oriente como ocurriera con figuras de la talla de Chateaubriand, Lamartine o Laborde ${ }^{20}$.

El gran inconveniente para ellos y muchos otros era la distancia que habían de recorrer para acceder al conocimiento de aquellas exóticas maravillas. Fue ahí donde España empezó a jugar un papel destacado ya que se convirtió en el lugar ideal donde conocer el legado oriental sin salir de Europa. Granada, Sevilla y Córdoba eran referentes del momento y se establecieron como visita obligada de los amantes de las formas islámicas con lo que la imagen romántica de nuestro país se acababa completando. Al ingente patrimonio cristiano medieval se unía el descubrimiento de esas nuevas antigüedades que propiciaban la inclusión de España en el repertorio pintoresco europeo digno de conocer.

La consecuencia más notable de estas novedades se tradujo en un interés inusitado por conocer y salvaguardar los monumentos y cualquier otro resto relacionado con la cultura islámica que durante siglos se asentó en la península. Pero, además, se dejó notar en la arquitectura de nueva creación al retomarse sus formas como ocurriera con la arquitectura gótica.

El neoarabismo hizo acto de presencia en el siglo XIX aunque acompañado de una cierta confusión debido a la variedad que en el mismo se incluía. En la arquitectura árabe se comprendían los estilos emiral, califal, almorávide, almohade, nazarita e incluso mudéjar. Asimismo, aunque fueron numerosos los edificios construidos en clave árabe, lo cierto es que se trató de un estilo un tanto marginado ${ }^{21}$.

${ }^{20}$ MARÍ, Antoni, "Oriente y la voluntad de expresión romántica”, en PASTOR MUÑOZ, Mauricio (com.), La imagen romántica del legado andalusí, catálogo de la exposición, (Almuñecar, 1995), Granada, Lunwerg, 1995, pp. 145 y 146.

${ }^{21}$ El uso de la estética orientalista se centró básicamente en la construcción de palacetes o estancias especiales en el interior de alguno de ellos, plazas de toros, kioscos o casas de baños, todo ello un repertorio 
Este amplio contexto cargado de cambios quedó reflejado en las memorias de restauración que los arquitectos redactaron para muchos de los proyectos desarrollados en nuestro país. En esta investigación se escogieron para su estudio un total de 6 monumentos que pertenecían al medievo, concretamente a los estilos románico, gótico e islámico, ya que, debido al auge del medievalismo, era en los documentos de sus restauraciones donde mejor se constataba el cambio intelectual de la época. Así, se eligieron la iglesia de San Martín de Frómista en Palencia, la Basílica de San Vicente de Ávila, la Catedral de León, el Monasterio franciscano de San Juan de los Reyes de Toledo, la Mezquita de Córdoba y La Alhambra de Granada.

Estos monumentos experimentaron numerosas intervenciones de restauración y conservación a lo largo del siglo XIX e incluso en los inicios del siglo siguiente pero no todas fueron incluidas en la tesis. Concretamente, se eligieron aquellas de cuyas memorias se podía extraer de manera clara la ideología romántica y la nueva estética basada en la exaltación de la Edad Media. En las memorias de los proyectos los arquitectos restauradores aportaban datos que nos hablaban del nuevo gusto artístico que estaba rigiendo la sociedad, al margen de imposiciones academicistas. Así, la detenida lectura de los textos que las componían permitía extraer la esencia romántica que finalmente se terminaba plasmando en los resultados de los trabajos que en ellas se proponían. El propósito de la investigación en la tesis doctoral no fue el de exponer meramente los datos de cada uno de los procesos de restauración, sino plantear un análisis de los mismos desde parámetros más estéticos. Cada una de las líneas de las memorias dejaba ver los gustos de la época que marcaban irremediablemente el destino de los monumentos. El que el arquitecto optara por una u otra opción a la hora de intervenir venía determinada por los modos de pensamiento en los que se había formado.

Acerca de la restauración de la catedral leonesa nos centramos en el análisis de las acciones llevadas a cabo por tres de sus numerosos arquitectos-restauradores $^{22}$ : Matías Laviña, Andrés Hernández Callejo y Juan de Madrazo y Kuntz. La elección de sus trabajos responde exclusivamente a que sus intervenciones dieron mucho juego para la reflexión estética del momento por centrarse en zonas de añadidos arquitectónicos posteriores. Fueron ellos los primeros en cuestionar la conveniencia de esos aditamentos y la necesidad de acabar con

\footnotetext{
bastante reducido. Véase HERNANDO, Javier, Arquitectura en España, 1770-1900, Madrid, Cátedra, 2004, pp. 231 y 232.

${ }^{22}$ La catedral de León es uno de los monumentos más intervenidos de nuestro país. Para conocer más acerca de sus restauración se pueden consultar algunas obras entre las que podemos destacamos las siguientes: RIVERA, Javier y ARRECHEA, Julio I. (eds.), Demetrio de los Ríos. La Catedral de León, Valladolid, Ediciones Ámbito y Diputación de León, 1989 (edición facsímil); RIVERA, Javier, Historia de las restauraciones de la Catedral de León. "Pulchra leonina": la contradicción ensimismada, Valladolid, Secretariado de Publicaciones de la Universidad, 1993; GONZÁLEZ-VARAS, Ignacio, La Catedral de León: Historia y restauración (1859-1901), León, Secretariado de Publicaciones de la Universidad, 1993.
} 
ellos para conseguir la "catedral tipo" que se preconizaba por la restauración violletiana (fig.1).

El monasterio franciscano de San Juan de los Reyes supuso en este trabajo el poder acercarnos a una forma distinta de ver la estética gótica durante el XIX. San Juan encarnó la evocación romántica por excelencia gracias a los numerosos daños que había ido sufriendo. Éstos habían creado en él una imagen desoladora a la vez que tremendamente atrayente para el romántico por lo que sus ruinas permitían inventar relatos misteriosos que hallaban el escenario perfecto en aquellos restos de la magnificencia pasada. Esas ruinas, que fueron tan destacadas por los más insignes literatos como el propio Becquer ${ }^{23}$, eran admiradas pero no por ello se perpetuaron eternamente. La tendencia restauradora también llegó a ellas, especialmente en la zona del claustro que fue la más duramente azotada por el tiempo y los acontecimientos. El monumento había quedado marcado para siempre por los daños experimentados durante la invasión napoleónica ${ }^{24}$. Una vez acabada la guerra y tras la vuelta de la congregación, se dieron diversos intentos por recuperar el lugar a lo largo de las décadas siguientes y, finalmente, en 1816 se iniciaron las tareas de desescombro del claustro (fig.2) con el fin de recuperar las piezas que lo habían conformado pero las obras nunca se finalizaron debido a la llegada de la Desa-

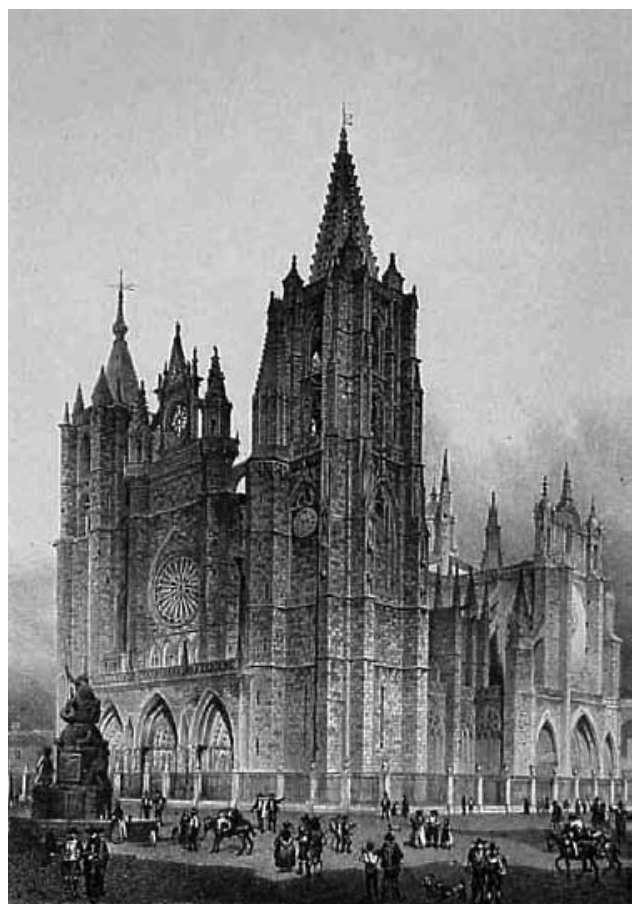

Fig.1. Imagen de la catedral de León donde aún aparecen elementos eliminados con las restauraciones como la cúpula central del cimborrio y los remates de los hastiales, todos ellos de tradición barroca. Obra de Francisco Javier Parcerisa para la colección Recuerdos y Bellezas de España (1839-1865).

23 Véase BÉCQUER, Gustavo Adolfo, San Juan de los Reyes, Madrid, Imprenta de M. Anguiano, 1900; Id., Templos de Toledo, Toledo, Zocodover, 1989; Id., Historia de los Templos de España. Toledo, Toledo, Antonio Pareja Editor, 2005.

${ }^{24}$ Éstos fueron de sobra conocidos, como queda patente en la relación de los hechos realizada por Fray Francisco Gómez Barrilero. El religioso, a la llegada de los invasores, se refugió en una casa cercana al monasterio desde donde pudo asistir en primera persona al incendio y destrucción del recinto que después dejó por escrito. Existe un interesante artículo monográfico sobre este documento. Véase ABAD PÉREZ, Antolín, "Relación sobre el incendio de San Juan de los Reyes (1808) y vicisitudes posteriores hasta 1864", en Toletum, no 4, 1969, pp. 169-188. 


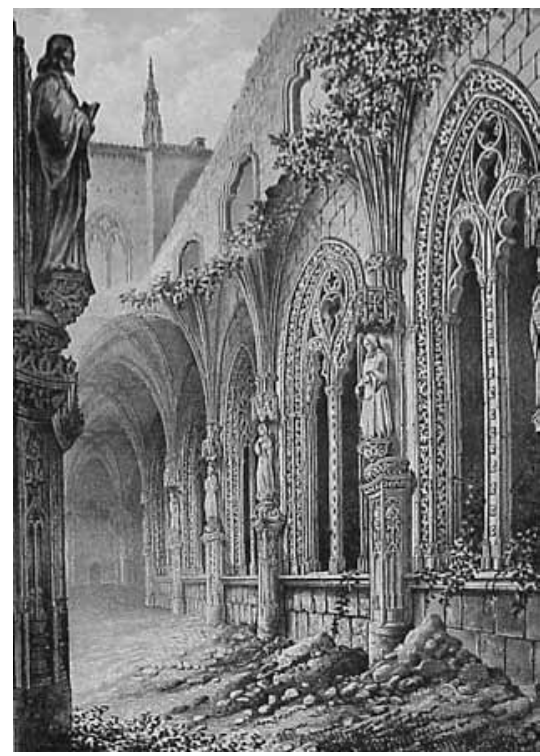

Fig.2. Claustro del monasterio de San Juan de los Reyes en Toledo con los daños sufridos tras la Guerra de la Independencia. Obra de Francisco Javier Parcerisa para la colección Recuerdos y Bellezas de España (1839. 1865). mortización $^{25}$. En noviembre de 1845, una vez asentada la Comisión de Monumentos en Toledo, el jefe político de la provincia solicitaba un informe sobre qué hacer con los conventos suprimidos. El día 28 del citado mes se acordó que el convento debía conservarse por el más que probado mérito artístico de su iglesia y claustro $^{26}$. La restauración más importante que experimentó el lugar fue la llevada a cabo por Arturo Mélida Alinari, la cual fue una restauración orientada a la búsqueda de una depuración formal que significó la culminación de un proceso que se había iniciado mucho antes ${ }^{27}$.

La restauración de la iglesia de San Martín en la localidad de Frómista (fig.3) fue llevada a cabo por el arquitecto Manuel Aníbal Álvarez y Amoroso a través de tres proyectos que vieron la luz a lo largo de los años 1895, 1896 y 1901. Aunque pueda parecer que los citados proyectos son excesivamente tardíos, lo cierto es que son una buena muestra de cómo aquellos pensamientos y sentimientos fraguados con el Romanticismo siguieron muy presentes durante décadas posteriores, a pesar de las críticas. La intervención se basó nuevamente en dotar al edificio de una supuesta imagen ideal que alteró para siempre la esencia original del recinto. Desde siempre estas intervenciones se vieron rodeadas de polémica dando como fruto interesantes debates acerca de la adecuación de las mismas que siguen vigentes hoy. Esas discusiones se han abierto a un público más amplio gracias a la publicación en los últimos años de obras dedicadas a analizar de manera individualizada la historia del edificio ${ }^{28}$.

25 FRANCO MATA, Ángela, "Toledo Gótico", en PERIS, Diego (coord.), Arquitecturas de Toledo, I: Del romano al gótico, Toledo, Servicio de Publicaciones de la Junta de Comunidades de Castilla-La Mancha, 1991, p. 521.

${ }^{26}$ MARTÍN SÁNCHEZ, Julio, "La arquitectura religiosa en Toledo durante los siglos XIX y XX: desamortización, restauración y nuevas consagraciones", en VIZUETE MENDOZA Juan Carlos y MARTÍN SÁNCHEZ, Julio (coord.), Sacra loca toletana: los espacios sagrados en Toledo, Cuenca, Ediciones de la Universidad de Castilla-La Mancha, 2008, p. 418.

27 La memoria original se encuentra depositada en la Escuela de Arquitectura de Madrid aunque también publicada en edición facsímil en NAVASCUÉS PALACIO, Pedro, "Mélida y San Juan de los Reyes de Toledo", en NAVASCUÉS PALACIO, Pedro (coord.), Isabel la Católica: reina de Castilla, Barcelona, Lunwerg, 2002, pp. 331-355.

28 En este sentido véanse SENRA GABRIEL Y GALÁN, José Luís, "Origen, muerte y resurrección de la Iglesia de San Martín de Frómista”, RODRIGUEZ MONTAÑÉS, José Manuel, "Cronología de la res- 


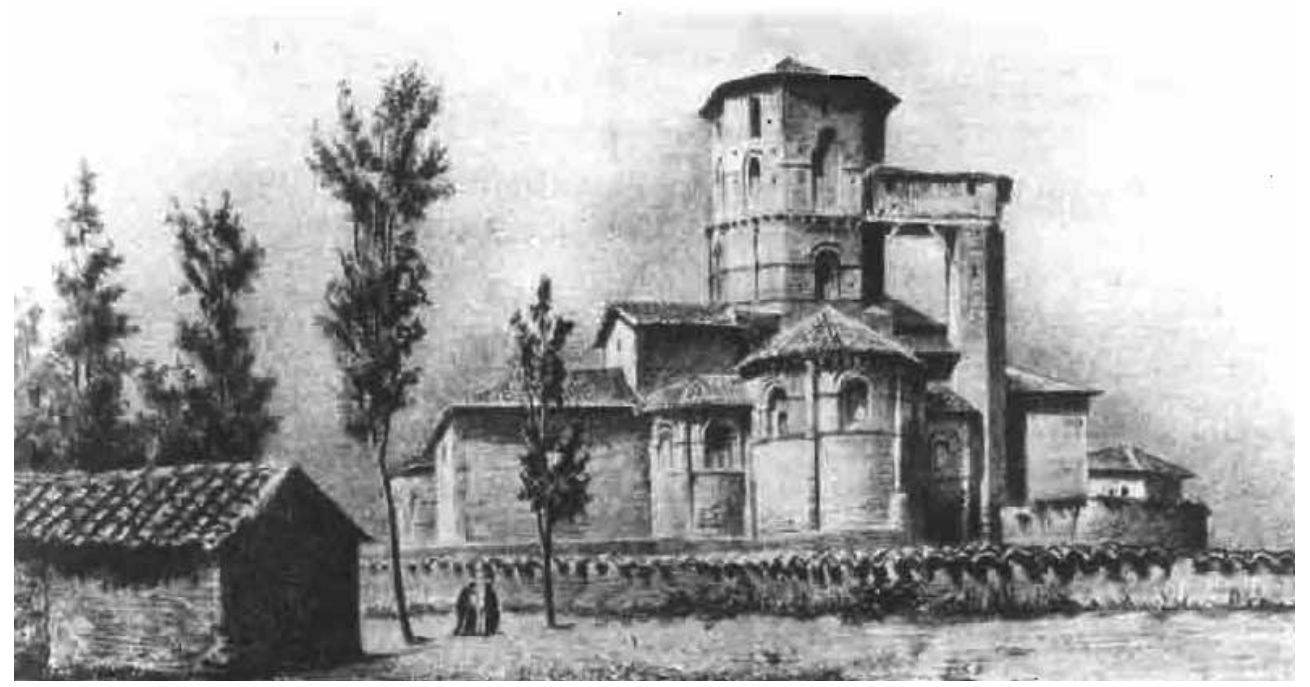

Fig.3. Iglesia de San Martín de Frómista antes de la exhaustiva restauración que devolvió al monumento una pretendida imagen original. Litografía de Francisco Javier Parcerisa, 1860.

El caso de la restauración de la iglesia de San Vicente en Ávila es especial ya que, mientras la mayoría de las restauraciones abordadas en la tesis tenían como fin dotar a los edificios de unidad estética eliminando añadidos muy posteriores a la creación original de la edificación, en el caso de San Vicente se buscó la limpieza formal pero destruyendo partes que databan del origen del recinto. Así, la intervención implicó la destrucción de vestigios góticos que formaban parte de la construcción inicial ya que la iglesia aunque se comenzó en estilo románico se acabó en gótico. Por tanto, no deberían haber sido considerarlos como adiciones posteriores sino como una etapa más en la creación de la iglesia. Los trabajos que han sido analizados corresponden a las intervenciones de Vicente Miranda y Enrique María Repullés ${ }^{29}$.

tauración de San Martín de Frómista”, RIVERA, Javier, "San Martín de Frómista y la restauración española en el cambio del siglo XIX al XX" y HERNANDO GARRIDO, José Luís, "El contexto de la restauración de San Martín de Frómista (1895-1904): «El edificio de la gran patria castellana» y la propaganda política”, todos ellos en RIVERA, Javier, Frómista 1066-1904. San Martín, centenario de una restauración, Valladolid, Fundación del Patrimonio Histórico de Castilla y León, 2004. Igualmente, véanse HERNANDO GARRIDO, José Luís, "Apostillas a la restauración de San Martín de Frómista (1895-1904): el contexto sociopolítico", GALLEGO FERNANDEZ, Pedro Luís, "Aníbal Álvarez y la restauración de San Martín de Frómista” y GARCÍA GUINEA, Miguel Ángel, "Criterios y opinión general sobre los discutidos problemas que parecen perseguir desde hace tiempo a la conocida iglesia románica de San Martín de Frómista”, todos en RODRIGUEZ MONTAÑÉS, José Manuel (coord.), San Martín de Frómista ¿paradigma o historicismo?, Valladolid, Fundación del Patrimonio Histórico de Castilla y León, 2005.

29 Véase la tesis doctoral de FEDUCHI CANOSA, Pedro, La Basílica de San Vicente de Ávila, Director: Rafael Moneo, Universidad Politécnica de Madrid, Escuela Técnica Superior de Arquitectura, 2007. http: // oa.upm.es/1044/ 
Por su parte, la mezquita de Córdoba contaba con una valoración positiva como monumento sin par en todo el mundo. La singularidad que lo acompañaba era motivo suficiente para que el mundo de la cultura velara por su integridad con el fin de prolongar su existencia en el tiempo lo máximo posible. En base a ello, la recuperación de la mezquita se convirtió en uno de los grandes objetivos del momento. En este sentido, las obras de restauración que nos interesaron para su estudio fueron las llevadas a cabo por Ricardo Velázquez Bosco quien trabajó allí desde 1891 hasta 1912 aunque en la tesis nos centramos exclusivamente en los primeros proyectos ${ }^{30}$. Como él mismo planteaba, la intervención tuvo como objetivo primordial eliminar los añadidos que con el paso de los años había adquirido la mezquita original, siguiendo así la tónica general de la restauración decimonónica. De este modo, el criterio de la pureza estilística se manifestaba también en un edificio árabe de la misma manera que venía ocurriendo con los edificios fundamentalmente góticos y románicos. Lo importante era recuperar la imagen de un monumento idealizado donde pareciera que el tiempo nunca hubiera pasado y si para ello era necesario romper con la historia del mismo, se hacía sin problemas.

Por otra parte, desde que Granada cayera en manos cristianas La Alhambra había sufrido daños aunque casi a la vez se acometieron las primeras reparaciones. Los Reyes Católicos la establecieron como palacio real y para ello la restauraron empleando para a maestros moriscos que recuperaron las zonas dañadas siguiendo de manera literal el estilo islámico. El interés por mantener el recinto siguió hasta que llegado el siglo XVIII las preferencias cambiaron con la imposición de la estética clasicista. Ya en el XIX se volvió a insistir en la necesidad de hacer algo para mantener el monumento tras el terremoto que había afectado la ciudad en 1806. Además, con la llegada de las tropas francesas, la fortaleza fue usada como gran cuartel general dando lugar a uno de los episodios más negros en su historia ${ }^{31}$. En estos inicios del siglo XX los maestros de obra, Tomás López y José de Salas, encargados de velar por la integridad de la ciudadela islámica poco o nada hicieron y la mala situación se agravó en 1822 con un nuevo terremoto. Como consecuencia, en 1827 se nombró a José Contreras y a Antonio López Lara como encargados de las obras ${ }^{32}$ e iniciados los años treinta, se comenzaron las restauraciones más ex-

30 En concreto se han trabajado las siguientes memorias: Obras de restauración de la Catedral de Córdoba, Memoria de Ricardo Velázquez Bosco, Madrid 28 de enero de 1891, Archivo General de la Administración, 05 (014) 31/08044; Catedral de Córdoba. Proyecto de obras adicional al de Reposición de Pavimentos, Memoria de Ricardo Velázquez Bosco, Madrid 10 de marzo de 1899, Archivo General de la Administración, 05 (014) 31/08375; Proyecto de Restauración de la Capilla de Villaviciosa (Bóveda central de los pies de la maksura) en la Catedral del Córdoba, Memoria por de Ricardo Velázquez Bosco, 28 de noviembre de 1907, Archivo General de la Administración, 05 (014) 31/08375.

31 Se generaron infinidad de destrozos y alteraciones especialmente en el Patio de los Leones. Véase ORDIERES, Isabel (1995), op. cit., p. 160.

32 BARRIOS ROZÚA, Juan Manuel, "La Alhambra de Granada y los difíciles comienzos de la restauración arquitectónica (1814-1840)", en Boletín de la Real Academia de Bellas Artes de San Fernando, n 106-107, 2008, pp.131-135. 
haustivas de algunos de los lugares emblemáticos de La Alhambra como el Generalife y los propios palacios nazaríes. En esos años se dio un momento clave ya que se inauguraban las restauraciones románticas por excelencia con Rafael Contreras ${ }^{33}$. En sus intervenciones se aglutinaban todas las características prototípicas de un retorno ideal en una arquitectura maltrecha que no era ni el reflejo del reflejo de lo que pudo ser en otra época. En las intervenciones decimonónicas de la Alhambra primaba lo decorativo a lo estructural, de manera que Contreras no dudó en hacer y deshacer a su antojo introduciendo partes totalmente nuevas hasta lograr una imagen perfecta e ideal. En este sentido, destacó su Memoria sobre las reformas que deben introducirse en la Alhambra para su posible conservación, fechada a 20 de noviembre de $1875^{34}$, donde quedó patente ese interés por la arquitectura prototípica islámica.

A modo de conclusión y tras haber estudiado estos ejemplos, hemos podido constatar como la importancia del Romanticismo para la historia general y el devenir de la restauración fue innegable, ya que se encuentra incluso en la base de las actuales teorías conservacionistas. Sorprendentemente y a pesar de ello, nos encontramos con que el Romanticismo no ha sido una etapa tan estudiada como ha ocurrido con otras épocas debido, muy posiblemente, a los problemas a la hora de definirlo. No existen unas características concretas que lo identifiquen como ocurre con otras manifestaciones artísticas, sino que se compone de una importante variedad formal e incluso ideológica. El marco cronológico en que se desarrolló es igualmente difícil de establecer ya que el Romanticismo tenía sus orígenes en el siglo XVIII y su influencia se mantuvo incluso hasta los inicios del siglo XX. Si bien es cierto que su momento de auge en España se dio desde la década de los años 30 del siglo XIX, es casi imposible hablar de fechas absolutamente cerradas. El Romanticismo no solo fue un movimiento artístico sino que fue, sobre todo, un movimiento ideológico guiado por el sentimiento del individuo, de ahí las inconvenientes para definirlo desde un punto de vista racional. Como dijo el propio Baudelaire, el Romanticismo era una "manera de sentir" y cómo tal debía entenderse ${ }^{35}$.

Si bien es cierto que muchas de las intervenciones llevadas a cabo al calor del Romanticismo no fueron del todo afortunadas, vistas desde la perspectiva actual, debemos tener muy presente que el Romanticismo en España buscó en todo momento el beneficio para el monumento. Las intenciones fueron buenas pero, desgraciadamente, los resultados no terminaron siendo los pretendidos inicialmente $y$, como consecuencia, se alteraron para siempre determinados monumentos provo-

33 GALLEGO ROCA, Javier, "Rafael Contreras y las restauraciones románticas de la Alhambra", en Restauración y rehabilitación. Revista Internacional del Patrimonio histórico, $\mathrm{n}^{\circ}$ 70, 2002, pp. 54-56.

34 "Memoria sobre las reformas que deben introducirse en la Alhambra para su posible conservación", Rafael Contreras, 20 de noviembre de 1875, Archivo General de la Administración, 05(014) 31/08044.

35 BAUDELAIRE, Charles, Salones y otros escritos sobre arte, Madrid, Visor, 1999, p. 103. 
cando con ello el falseamiento de la Historia del Arte nacional jalonada de pastiches arquetípicos.

Sea cual fuere el resultado, lo que parece claro es que si el Romanticismo no hubiera aparecido, la historia de los monumentos españoles nunca hubiera sido la misma. Si no se hubiera revalorizado la Edad Media y se hubieran continuado los preceptos neoclásicos, hubiéramos asistido a la muerte progresiva del patrimonio medieval. Igualmente, nunca se habrían puesto las bases para la aceptación de todas las manifestaciones del arte y jamás se hubiera acabado con las jerarquías estilísticas. El Romanticismo, por tanto, debe ser reconocido como uno de los grandes revulsivos de la creación artística, de la reflexión estética y del campo de la restauración monumental de la era contemporánea. 